\title{
Study of promises for the use of ultrasound in the technology of secondary benefication of processing wastes
}

\author{
Olga Voronova $^{1 *}$ and Lidiya Kienko ${ }^{1}$ \\ ${ }^{1}$ Mining Institute of Far Easten Branch of Russian Academy of Sciences, Khabarovsk, Russia
}

\begin{abstract}
The results of the study, aimed at designing of benefication technology of mine processing wastes of Voznesenskiy ore district, are presented in this paper. By the expert appraisals, the amount of tailings dumps of the Yaroslavskaya Mining Company is estimated to be more than 30 million tons. Sample testing has shown that fluorite content varies from $13 \%$ to $23 \%$, calcite - up to $14 \%$, and zinc - in the range of $0.4-0.6 \%$. The research was conducted with tailing samples containing $20.7 \%$ of $\mathrm{CaF}_{2}$ and $10.2 \%$ of $\mathrm{CaCO}_{3}$. Mineral grains of the secondary raw material were examined for their surface state and a package of necessary preliminary operations, which provide an efficient material - flotation reagents interaction, was determined. It has been established that extraction of fluorite to concentrates that would match existing requirements is possible in principle. The use of ultrasonic treatment of material in its preparation for flotation is conditioned by an effective desorption of films of different nature from mineral particles. The suggested scheme of fluorite flotation involves preliminary treatment of raw material by ultrasound with dumping of released mud fractions. The optimal operating regime allows obtaining concentrates of higher quality than it is under usual technology without the ultrasonic exposure. In this process, the extraction of fluorite to a concentrate with $94.47 \%$ of $\mathrm{CaF}_{2}$ increases up to $61.11 \%$, which is higher by $2.96 \%$ against the original studies.

Key words: mineral mining and processing wastes, fluorite, surface formations, ultrasound, desorption, mud fraction, flotation concentrate.
\end{abstract}

\section{Introduction}

The major factor of achieving high efficiency of flotation in the processing of low-grade difficult raw material and processing waste is the creation of conditions for selective adsorbation of reagents on the surface of mineral particles. For the finely disseminated ores, which require fine size degradation, the problem of surface purifying is conditioned by the presence, in prepared material, of a huge amount of mud with the developed surface which surrounds particles of productive size, combining into non-selective aggregate $[1,2]$. In the process of mine wastes dressing the problem is aggravated, since mineral grains' surface

* Corresponding author: olya-vo@mail.ru 
has residuals of reagents used at the stage of primary processing, various formations conditioned by the long-term storage in the salt-water environment [3]. To ensure necessary contact of mineral particles with reagent and further selection it is essential to supplement the flotation scheme with the operations of surfaces desorptions. Meanwhile, the separation into a different product with further removal from the scheme of desorbed chemical and mechanical surfaces, in order to avoid their negative effect on the technology' further processing, is relevant.

\section{Materials and methods of research}

Desorption can be performed with the usage of different methods: mechanical, chemical, physical-chemical, and methods based on usage of complicated energetical impulses. One of the most perspective directions is usage of ultrasonic machining. A wide range of different transformations follows the ultrasonic machining of rock slurries. According to the studies of Agranat B. A., Glembotskiy V. A. and others [4-6], the influence of acoustic vibrations on hydro-mineral mixes can be multi-faceted. Thereby, the physical-chemical characteristics of liquid phase, the characteristics of adsorptive and hydrate layers on the surface of mineral particles are changing. Transformation of different physical-chemical characteristics of pulp can be happening under the effect of ultrasound, e.g. conductivity, oxidation-reduction capability, water $\mathrm{pH}$. Moreover, possible destruction of carboxycontaining compounds' colloidal structures, which are used in the flotation process of the majority of calcium minerals, can be followed by increase in dispersibility level of used collectors, intensification of flotation reagents' action, and decrease in their consumption. Traditional methods of mineral surface cleaning are chemical and heat treatment, mechanical rubbing usually doesn't guarantee necessary quality of cleaning, especially cleaning from filming and impurities located in micro fractures and holes. The usage of ultrasound for these purposes seems to be very promising. The removal of natural films and coats together with secondary formations from the surface of mineral particles improves the contact of flotation reagents with a mineral and supports the activations of adsorptive processes [7-9].

Nowadays the usage of processing wastes is the most promising direction of solving the problem of raw material sources shortage for a range of manufacturers in the mining industry. According to the current data, the amount of fluorite ores processing tailings in the tailing dump of Yaroslavskaya Mining Company (YMC), located in the Voznesenskiy ore district (VOD), Primorskiy region, is estimated to be more than 30 million tons. The contains of fluorite is within $13-23 \%$, of calcite - not more than $12-14 \%$. The average number of carbonate module $\left(M_{\kappa}=\alpha_{\mathrm{CaF}_{2}} / \alpha_{\mathrm{CaCO}_{3}}\right)$, which mostly defines the enrichability of carbonate-fluorite ores, amounts in $1.4-1.6$. Moreover, available for mining ores of VOD contains no more than $26-29 \% \mathrm{CaF}_{2}$ and less than $20-25 \% \mathrm{CaCO}_{3}$. All of the ores, being primary raw materials of the company, are considered to be complex ores. The main reasons for this are - extremely thin mutual intergrowth of mineral phases, presence of tiny growths, additional minerals and calcium components, which are close to flotation by characteristics, on the fluorite particles [10]. In technogenic tailings fluorite is presented by the most problematic grains, which were not extracted at the stage of primary benefication. The content and characteristics of processing material determine the necessity of special way of technological evaluation.

The research of possibility of getting fluorite concentrates from processing material was made on the material of tailing sample, taken from the tailing dump of dressing plant of YMC. The chemical analysis discovered the following contents of main components: $\mathrm{CaF}_{2}$ $-20.7 \%, \mathrm{CaCO}_{3}-10.2 \%, \mathrm{SiO}_{2}-32.2 \%, \mathrm{Zn}-0.38 \%$. During the conduction of research 
there have been found technological solutions, which can assure the possibility of fluorite concentration together with the achievement of satisfying figures due to rational selection of disruption mode, $\mathrm{pH}$ environment in main fluorite flotation and usage of selectively operating compositions of modificators and collectors [11]. During the abovementioned process the concentrates have been extracted, containing more than $93 \%$ of $\mathrm{CaF}_{2}$ with the extraction of $58-60 \%$ of fluorite. The decrease of $\mathrm{CaF}_{2}$ content for $1-1.5 \%$ gives the possibility to boost the extraction (for $10 \%$ and more) due to the redistribution of the most contaminated with additives fluorite grains. That is why the research of influence and additional preparation of flotation feed, aimed at cleaning of mineral grains, desorption from the particles' surface of different chemical, slurry and other coverings, is worth noticing. The additional preparations of the surface can be followed by a reasonable increase of desorption processes selectivity and relevant rise in the quality of concentrates.

\section{Results and discussion}

The research of optimization of the process of flotation' fluorite extraction from the processing materials with the usage of ultrasonic machining of given material was based on the scheme, given at the fig. 1.

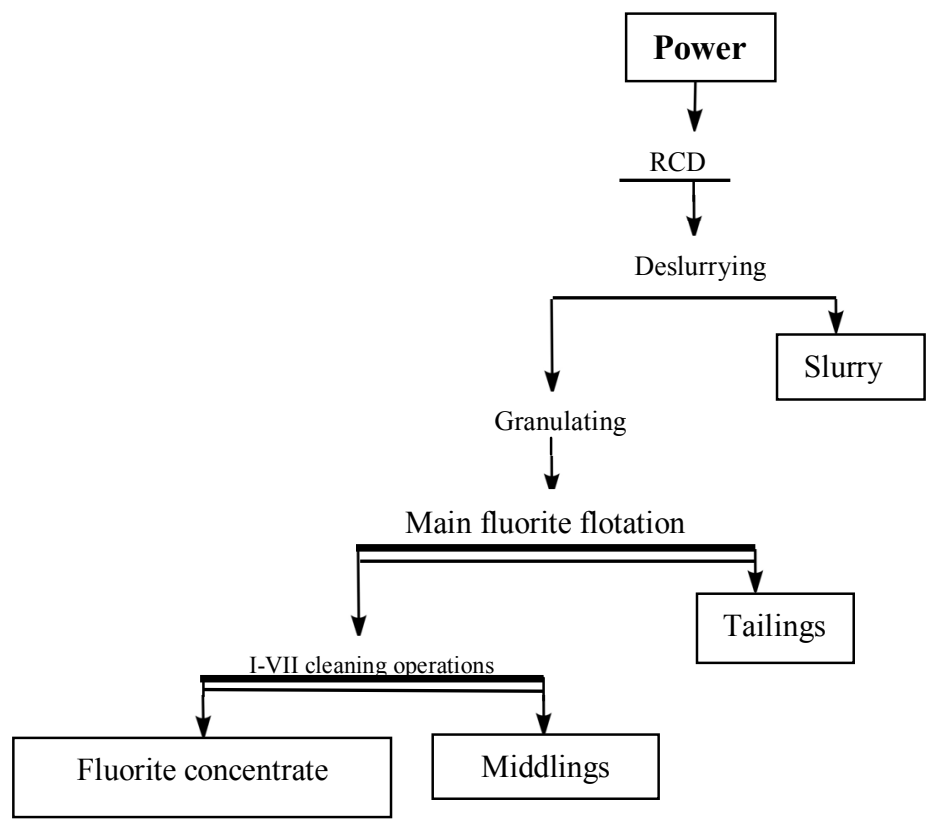

Fig. 1. The scheme of processing tailings flotation with the preliminary ultrasonic desorption of primary cleaning circuit surfaces.

The ultrasonic machining was used on the researched material at its original feed size, before being granulated. The machining was processed with the use of ultrasonic device IL100-6, produced by Saint-Petersburg company "Ultrasonic equipment INLAB". The ultrasound operating frequency $-22 \mathrm{kHz}$. The operation time $-7 \mathrm{~min}$, which was calculated based on results received earlier, in our ore-based research [12]. Desorbed chemical compounds and slurry particles were extracted into separate product and removed from the scheme, because the possibility of negative impact on the further technology processing is rather high. 
The flotation of abovementioned material was done with the usage of TOFA as of collector, modificators - mix of ammonium fluoride salts and lignosulfonates. Depending on the consumption of main reagents (three modes) the concentrates of different quality were extracted. The results of experiments, given at the fig. 2, show major influence of ultrasound on the process. After the treatment we had a chance to get concentrates with the $\mathrm{CaF}_{2}$ content 93.5 - $94.47 \%$, against $93.46 \%$ in the experiment, conducted without preliminary insonation. At the same time we can see the growth of fluorite extraction for $2.27-2.96 \%$.

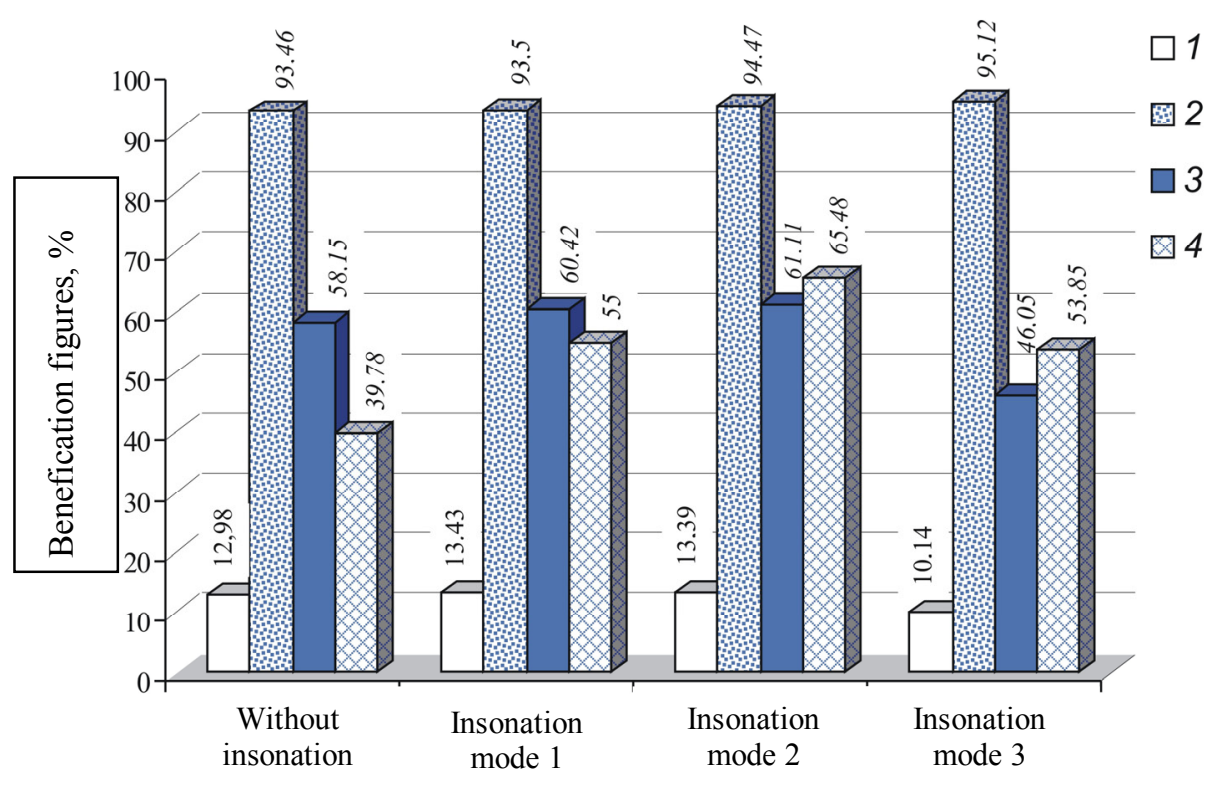

Flotation preparation mode

Fig. 2. Comparative figures of fluorite benefication from the processing tailings with and without ultrasonic treatment of given material: 1 - concentration ratio; $2-\mathrm{CaF}_{2}$ content in the concentrate; 3 fluorite extraction; 4 - selectivity index of fluorite and calcite.

At the experiments with the hardest mode of carbonates drop (mode 3) the concentrate with content of $\mathrm{CaF}_{2} 95.12 \%$ was extracted. The extraction of fluorite in these conditions decreased till $46.05 \%$. Taking into account that current consumers' market demand for high-quality fluorite concentrate of brand FF-95, FF-97 has notably grown, the result achieved is worth attention. According to the previously made research, during the usual mode flotation, without the usage of ultrasound, the fluorite extraction into high-quality concentrate with the content of $\mathrm{CaF}_{2}$ being $95.07 \%$ accounted for $40.7 \%$.

Acoustic effects let us increase the extraction for more than 5\%. Moreover, it is worth mentioning that experiments with the moderate mode of proportion mix of collector and modificators (mode 2) resulted in getting the concentrate with the $\mathrm{CaF}_{2}$ content of $94.47 \%$, which is quite close to the requirements for the concentrate brand FF-95. The extraction of fluorite in this case is reasonably higher $(61.11 \%)$.

The content of silica, which is harmful additive and is limited due to the All-Union State Standard (GOST) and technical conditions, is estimated for $1.9-2.3 \%$, which is suitable for brands FF-92, FF-92-A. 


\section{Conclusions}

Therefore, the usage of ultrasound at the stage of preparation for flotation of processing wastes aimed at desorption of primary processing reagents tailings and different coatings with the further separation of slurry fraction ensures effective preparation of mineral particles to the intercommunion with collectors.

In the optimum technological performance with the preliminary processing of materials it is possible to get a concentrate with the content of $94.47 \%$ of $\mathrm{CaF}_{2}$ with the extraction of $61.11 \%$ of fluorite. The extraction of fluorite into high-quality concentrate, containing $\mathrm{CaF}_{2}$ $95.12 \%$, decreases down to $46.05 \%$.

In the usual technological performance, without the usage of ultrasound, in all other equal conditions, the extracted concentrate contains $\mathrm{CaF}_{2} 93.46 \%$ with the extraction of $58.15 \%$.

\section{References}

1. V. I. Klassen, D. I. Nedogorov, I. Kh. Deberdeev, Slurries in the flotation process 160 (M.: Mineral resources, 1969).

2. L.A. Kienko, O.V. Voronova. Phys. Tech. Prob. Sol. Minerals, 1, 176 (2014).

3. L.A. Kienko, O.V. Voronova, S. A. Kondratyev. Phys. Tech. Prob. Sol. Minerals, 1, 158 (2017).

4. B. A. Agranat, M.N. Dubrovin, N. N. Khavskiy, The basics of physics and ultrasonic engineering, 352 (Moscow, 1987).

5. V.A. Glembotskii, M.A. Sokolov, I.A. Iakubovich and others Ultrasound in mineral deposits beneficiation. 212, Almaty (1972).

6. C. Letmahe, B. Benker, L. Gunther, Intensification of foam flotation using ultrasound, 43, No. 4, 32, (2002).

7. L.A. Kienko, O.V. Voronova, Zh.A. Shagina. Problems of comprehensive development of geological resources: Materials of VI National scientific conference with the participation of foreign scientists. Khabarovsk, 21, 233-241 (05-07 October 2016)

8. H. Mitome, Action of ultrasound on particles and cavitation bubbles, Proc. World Congress on Ultrasonics, Paris, 2342 (2003).

9. S. G., Ozkan, H. Z. Kuyumcu. Ultrasonics Sonochemistry, 14, 639 (2007).

10. L.A. Kienko, L.A. Samatova, O.V. Voronova, L.N. Plusnina. Economics and problems of mineral resources exploitation, MIAB, Far East, 9, 302 (2007).

11. L.A. Kienko, O.V. Voronova. III National scientific-practical conference Geomechanical and geotechnological problems of mineral resources exploitation of the North, Yakutsk, MIAB, SV 30, No. 7, 213 (2015).

12. L.A. Kienko, L.A. Samatova, O.V. Voronova. Promlems of comprehensive development of geological resources. Materials of $\mathrm{V}$ National scientific conference in Khabarovsk city, Mining information-analytical bulletin, Instalment 4. 172 (2013). 